\title{
Ontological Continuity in the Modern World-System: Agency, Areas, and the Structures-of-Knowledge Approach*
}

\author{
GRANT KIMBERLIN**
}

\begin{abstract}
With the passing of Immanuel Wallerstein, it is worthwhile to take note of his contribution to problematizing the unit of analysis. Rather than the states-as-containers interpretation, Wallerstein contributed that spatiotemporal units of analysis could be more meaningfully discussed in terms of their interactions within a larger system. The more well-known of his arenas are the axial division of labor (economic) and the interstate system (political). The third, the structures-of-knowledge methodology, aims to expand the "broadly cultural" arena as well. This paper will consider his project of reasserting agency through structural metanarrative with suggestions for ways to use his analysis to lend greater continuity to area-knowledge at a crucial time of transition.
\end{abstract}

Keywords: World-Systems Analysis, The Structures of Knowledge, Immanuel Wallerstein, Area Studies, Agency-vs-Structure

* A special thanks to Reviewer \#2, whoever you are. This paper originally undertook the overly-ambitious task of meshing Wallerstein's insights with Wilfred Sellars' contributions to the conceptualist school of epistemology and the philosophy of mind. Thanks to the detailed comments I received I determined a better angle for this project would be to show how world-systems analysis sheds light on apprehending knowledge more generally and towards a recuperation of agency and area, with a more limited focus on ontology. Thanks again.

** Lecturer, Pukyong National University, Busan, South Korea;

E-mail: grantkimberlin@gmail.com;

DOI: 10.16934 isr.21.1.202006.99 


\section{INTRODUCTION : The Arenas of the Modern World System}

Considering the recent passing of Immanuel Wallerstein just short of his founding project of world-systems analysis' fiftieth anniversary, it's worthwhile to take stock of the insights this intellectual movement has inspired. Notably, Wallerstein (2012) had insisted that his was not a theory, more a "knowledge movement", a metanarrative project of substituting the unit of analysis from "the state" to a more thoroughgoing "world-system", crucially hyphened to emphasize this unit referred not to the world but that it was a world unto itself.

The modern world-system, however, with few exceptions (pockets of the Amazon or the North Sentinel Islands, perhaps) has incorporated, in his parlance, the entirety of the globe. It has done this through the use of a capitalist world-economy originating from an axial division of labor in "a western European core where high-wage, skilled workers produced low-bulk, high value-added products and an eastern European periphery where high-bulk, low value-added necessities were produced under a regime of lower-cost labor" (Lee 2012a, 162). Politically, these zones were regulated under the interstate system, what Perry Anderson (1974) referred to as a system of "parcellized sovereignty" among "states with reciprocal rights and obligations, at least to the extent that their territorial extensions and the monopoly on the use of force within them, were recognized by other states" (Lee 2012a, 163).

These arenas that concern "distribution and production"(economics) and "decision-making and coercion" (politics) have been the most developed. As Richard Lee (2012a, 164) writes, "what is still up in the air, however, is the status of those other elements of social life that have to do with the production of meaning." As Director of the Fernand Braudel Center for Historical Sociology, Lee has carried on Wallerstein's project through the structures-of-knowledge approach, a third analytically distinct arena he calls the "arena of cognition and intentionality." These structures, Lee $(2012 b, 105)$ writes "focus on what is possible and legitimate to think (and therefore do) in a given society." This has been done through the divorce and subordination of human values beneath so-called "disinterested calculations" in the vein of C.P. Snow's (1959) famous allusion of the "two cultures." - in short, the elevation of scientific fact over human value.

Key to world-systems analysis are that its arenas undergo "medium-term fluctuations expressing the realignments that have assured the reproduction over the long term of the regularities under pressure from the contradictions endogenous to the system" (Lee 2003, 123). These fluctuations are often termed "waves" or "cycles" in the economic and political arenas. Re-appropriating Rondo Cameron's (1973) term, Lee refers to those taking place in the sociocultural realm "logistics" and each center around epistemic and ontological 
understandings as to what constitutes the basis for consensus. While "the interstate system organizes the application of force to assure acculturation" (Lee $2012 \mathrm{~b}, 105)$, the structures of knowledge discipline "the cognitive structures constraining consensus and dissent" (Lee 2003, 124). In so doing, it can be argued, these structures more effectively confront the reality that each individual has a mind fitted with an agency rendering them capable of thinking and doing anything at any moment. This central predicament problematizes any forwarding of structure, the categorical instantiations thereof, and the transformations therein be they national, regional, global, or any other sort.

Reimagining structure through the lens of human agency meant taking aim at the management of human cognition. Certainly the emphasis on unit of analysis was the main element in Wallerstein's knowledge movement, but he had always insisted that among other crucial elements (e.g. the historicity of systems) was the rejection of the nineteenth-century institutionalization of knowledge. This meant "the refusal of the ontological separation of the imagined arenas so dear to the old dominant set of premises-the political, the economic, and the socio-cultural" (Wallerstein 2012, 518). Instead, Wallerstein's project aimed at greater ontological continuity for knowledge and its subjects. Challenging the epistemic power that these and other categories hold has been central to the normative aspect of his project. World-systems analysis, in his words, would work "to challenge more fundamentally the previously dominant epistemological premises that had fashioned the so-called disciplines - as intellectual arguments, as organizational apparatuses, and as cultural phenomena" (ibid, 517).

Area-specific knowledge offers crucial insights but, and as shall be examined below, this usefulness has been underwritten and directed in a uniquely top-down fashion from the sort of challenges to the structures of knowledge that followed. These areas are but geographies if not for the many people that give these geographies meaning. World-systems analysis and the structures-ofknowledge methodology in particular offer a reversing corrective in demanding long-standing categorical distinctions are meaningless outside their informing content. Analyzing an area, be it a geographical space or realm of knowledge, depends, then, on considering how its operant mechanisms marshal the momentby-moment reproduction of human thought and behavior to lend continuity to form.

The development of this area-specific knowledge on which international studies so crucially depends will be examined below in light of world-systems analysis' attempt at excising essentialist categories and rearticulating agency through structuralist metanarrative. Wallerstein and other world-systems analysts have held that the current system is undergoing "bifurcation", the work done to liberate agency through analysis of what Wallerstein termed our "social prisons" by his movement will be explored below to offer a suggestion for how to analyze 
areas of agency in our bifurcating present. This finds powerful instantiation in the face of vast and protean challenges to a world that increasingly and desperately demands solutions beyond the constraining abstractions of states, regions, areas, economies, cultures, or political affiliations.

\section{Agency and the Quest for Objectivity: The Three Logistics}

Agency-centered critique and world-systems analysis may at first glance appear an odd association, not least to Wallerstein's critics. The state-autonomist critique of Theda Skocpol and Aristide Zolberg, inspired by the work of Otto Hintze, protested the inclusion of economic motivations into the political realm charging Wallerstein "deprives politics of any independent efficacy, reducing it to the vulgar expression of market-class interests." (Skocpol 1977, 1080). Similarly, the orthodox Marxist critique charged his core-periphery emphasis with "circulationism" and downplaying the role of production in the conflict between bourgeoisie and proletariat. Stanley Aronowitz, among others, critiqued, rather, his inability to escape orthodox Marxism and nomothetic positivism through Eurocentric, economic reductionism.

World-systems analysis' early attack on Eurocentrism and the fact that Andre Gunder Frank and Takeshi Hamashita were among the movement's brightest stars aside, Wallerstein had noted a central protest in these critiques: that of overlooking the role of a central actor. For nomothetic positivism it was the rational individual, for orthodox Marxism the industrial proletariat, for the cultural particularist it was each actor engaged in autonomous discourse with each other. Herein is one of Wallerstein's most surprising insights: treating agents as primordial elements structuralizes them, effectively robbing them of agency in the final analysis. Rather, he argued that to embed agents as parts and products of a system is to subject structure to their agency: "To the extent that we each analyze our social prisons, we liberate ourselves from their constraints to the extent that we can be liberated" (Wallerstein 2007, 21-22).

That these prison walls are also epistemic in nature is something not immediately apparent to many, and drawing attention to that feature of restraining structures was a big part of his life's work, especially the first 20 years of his movement of which he stated the main goal had been that of "clearing the underbrush, so that we may build a more useful framework for social science" (Wallerstein 1998, 103). Key to this was not just the positing of a world-system as analytic unit but also an analysis of the structures of knowledge that continue to lend it continuity. Let us examine these structures before considering their application to area-specific analysis.

Characteristic to Wallerstein, world-systems analysis aims not merely to 
critique the university system or any particular curricular program in isolation but reaches deep into the way knowledge conditions our notions of truth, beauty, justice, legitimacy, and all such categories that channel human agency - and it does so with no regard to separation between math and history, physics and cultural studies, chemistry and the fine arts.

The major thrust of the structures-of-knowledge approach has been to emphasize what Boris Stremlin $(2015,11)$ called "the germ of the structural differentiation, the separation of authoritative knowledge from social values unique in the history of human knowledge production, that has come to be known as the "two cultures." This separation between fact and value has come to be institutionalized in the sciences and humanities as an epistemological hierarchy with science on the top. Mary Poovey (1998) has traced the establishment of the modern "fact" as the prime unit of valid knowledge and cultural authority in Western thought from the $13^{\text {th }}$-century establishment of double-entry bookkeeping that came to elevate absolute mathematics over their medieval mystical essences (with exceptions like the unluckiness of 13). Lee $(2003,122)$ remarks on the effect this had in legitimating merchants as credible and creditworthy: "distinguishing profit from usury sanctioned the accumulation of accumulation." However, Poovey's insight was that of a broader cultural reconceptualization of knowledge exemplified in the use of two new terms: "disinterested' (in the sense of being unbiased by personal interest), which came into use about 1659, and 'interested' (in the narrower sense of self-serving), which was in use by 1705" $(1998,70)$. This dichotomy suggests an opening to a realm of human thought separated from the human, as though the observer could ever truly be removed.

Alfred Crosby (1997) had outlined that this stressed the homogeneity of time and space and representations of it through visual and quantitative units and nomothetic apprehension. This quest for objectivity had the effect, as expressed by world-systems scholars, of excising agency through a reconceptualization of experience to privilege the observation of particular observers - later experts over the Aristotelian, communal conceptions of the commonplace. The paradoxical task of eliding agency but relying on human observers took the form of appeals to natural laws, discoverable from "the view from nowhere" or by Kemmis and McTaggart's $(2005,570)$ brilliantly phrased "detached secretary of the universe." The ultimate effect still felt to this day has been the elevation of formal rationality - "disinterested calculation for the purpose of instrumental action" - over that of substantive rationality, or "the pursuit of normatively justified, specifically situated ends" (Lee 2003, 122).

From here, the structures-of-knowledge attempts to explain how this novel epistemology maintained continuity through forced corrections - logistics analogous to the rise and fall cycles of hegemonic powers in the geopolitical world and the expansion and contraction waves in the economic in pursuit of 
world-systems analysis' quest to "unthink social science", in Wallerstein's words (2001). These corrections exhibit how the system is able to manage agency and other uncertainties and reconstitute itself over time.

Accordingly, the world-systems tradition claims three distinct logistics beginning with the mechanistic model via the "Newtonian synthesis between Baconian induction and empiricism and Cartesian deduction and rationalism" (Lee 2011, 166) that saw the move away from God as the internal governing principle and towards creative potential being transferred to Locke's rational individual and sovereign majority. The product of enculturing this was perhaps best expressed by Oakeshott's $(1972,56)$ comment that "for Bacon and his near contemporaries 'education' stood, not for a transaction between the generations of human beings in which the newcomer was initiated into an inheritance of human understandings, sentiments, imaginings, etc.," but rather entailed "a release from all this in which he acquired 'objective' knowledge of the workings of a 'natural' world of uncontaminated 'things' and 'laws' and of himself as a feature of this world."

The second begins with the nineteenth-century creation of social science as a way to enlist the putatively value-neutral laws of the scientific realm in service of the putatively value-neutral category of "progress." The notion of being able to assert such discoverable laws seemed to offer certainty over the human realm and inserted itself between the major debates that characterized the age, such as the German Methodenstreit and the English order-vs-anarchy debates in order to "guarantee ordered change in the name of 'progress' and through 'scientific' control” (Lee 2012a, 165).

The third, reaches its apogee in the post-war presumption of U.S. hegemony and the institutionalization of separated disciplines with their own proprietary theories, methodologies and subject matters that compete with one another for funding. World-systems literature goes in depth to explain challenges that came about to undermine this logistic from women's and gender studies programs to complexity and chaos theory to anti-essentialist appeals across the disciplines, fractal geometry, the reclaiming of culture as a viable, primary analytic category, and the diffusion of myriad sub-disciplines that traverse the once solid boundaries of Western epistemology's authoritative knowledge.

It is this logistic that the world-systems perspective says is still reigning but severely weakening. The details and why they matter will be explained below, but let us in the following section consider how this legacy conditions area-specific knowledge and how the world-systems narrative contributes to enlivening such a project and that at which it takes aim. 


\section{Epistemic Roots and the Prolonged Present}

Where did area studies as a discipline come from? It's important to remember that the weakening of the third logistic both came (1) at its apogee and (2) not solely from the effect of dedicated, insurgent scholars. In 1943, the Committee on World Regions of the Social Science Research Council issued their internal report titled "World Regions in the Social Sciences." In it, the committee recognizes the dearth of non-Western regional expertise and recommends a knowledge project aimed at the "permanent interest to the United States" (knowledge of Japan, China, and Latin America). It suggests that the "laws and generalizations of the social sciences" can be grafted onto regional study enough to achieve "a weakening of the rigid compartments that separate the disciplines" (Wallerstein 1998, 196).

Initial funding would first come from U.S. Army attempts at outfitting their enlisted personnel and officer programs via their respective Foreign Area and Language Curricula of the Army Specialized Training Program (ASTPFALC) and Civil Affairs Training Schools (CATS). The focus would quickly shift after the war, of course, with Japan waning in importance to the Cold War concerns of the Soviet Union and, even more so, China. Nonetheless, planners had to mainly deal with the reality that the structures of knowledge hadn't yet been arrayed in such a manner as to provide for this application.

Wallerstein $(1997,197)$ reminds that "the fact that the United States had no 'regional specialists' in 1943 was the direct consequence of how the social sciences were institutionalized in the period 1850 to 1914 in the five key countries of the process: Great Britain, France, Germany, Italy, and the United States." In addition to the aforementioned subordination of value to modern fact, the disciplinary divisions also grew along epistemologies that were either nomothetic or idiographic. The former aims to discover laws or rules governing an area of analysis while the latter more closely aligns to the efforts of hermeneutics or interpretation, allowing for one's values in the role of judgment. History, though originally largely a hagiography of elites, was inherently idiographic and since it limited itself to the past the present-based disciplines of economics, political science, and sociology came to the fore. What is crucial about these disciplines for area studies are four key considerations: (1) their focus on the present, (2) their separation of the social world into distinct logics, (3) their nomothetic nature, and (4) their usefulness to the states and associations that financed their operations.

According to the world-systems metanarrative: this world came into being piecemeal via incorporation into the modern world-system under the Annales School of historiography's interpretation of capitalism as a system of endless capital accumulation despite existing in a limited world. The division of 
knowledge into disciplines occurred alongside and concomitant with this novel regard for "modernity" which was held to be divided into three separate spheres operating on their own logics. These disciplines could discover the laws governing the spheres of the market, politics, and, as an et-cetera category, society. That the Fernand Braudel Center is named as a place for "Historical Sociology" underscores that sociology was ordinally one of the present-based disciplines and that considering the historical contingency of the objects of study was something novel. Limiting themselves to an imagined present, the disciplines could posit abstract objects exerting force over their disciplinary domain and thus build nomothetic conclusions therefrom.

Abstract objects were originally said to exist outside of space and time, and thus one could diagnose "rational choice", "civilization", "intelligence", or "personality disorders", making objects by elevating prefigured categories over their informing content. A problem arises, however, since the category of modernity that gave rise to these displaces is itself a distinctly spatiotemporal one. Since the disciplinary practitioners originated from Western Europe the temporal achievement of modernity was said to be delimited to this area and thus the disciplines of anthropology and orientalism could justifiably study other parts of the world. Field research done in places like Africa where Wallerstein had done his original work prior to positing a world-system, was of course maligned as trapped in a primitive past, civilization occurring at the moment of contact with Western interlopers. The category of "high civilizations" took care of the messy reality that places like Persia and China constituted vast, complex, and often more advanced civilizations than those in Western countries but were argued to be frozen in place, unable to achieve modernity likely due to a rejection or separation from Christianity if not more menacingly for not being white.

With the later outgrowth and dominance of the American university system, this confused division "was worse than useless to policymakers in the United States.” Wallerstein $(2007,9-10)$ reminds:

"The United States needed scholars who could analyze the rise of the Chinese Communist Party more than it needed scholars who could decipher Taoist scriptures, scholars who could interpret the force of African nationalist movements or the growth of an urban labor force more than scholars who could elaborate the kinship patterns of Bantu peoples."

As a derivative to the category of modernity, the notion of "development" would reconcile the idiographic exercise of interpreting some delimited geographic space with the nomothetic pretentions of the Western-focused, present-based disciplines to fashion the U.S. invention of area studies. "Development, as the term came to be used after 1945, was based on a familiar 
explanatory mechanism, a theory of stages" Wallerstein (ibid, 10) writes, and though the nomothetic "national societies" bespoke the same soteriological trajectory they could do so at their own pace, explainable in interpretive (idiographic) terms. To quote Wallerstein (ibid) at length:

Presto! One would then be able to introduce specific concepts to study the "others" at the present time while arguing that eventually, all states would turn out more or less the same. This sleight of hand had a practical side as well. It meant that the "most developed" state could offer itself as a model for the "less developed" states, urging the latter to engage in a sort of mimicry, and promising a higher standard of living and a more liberal governmental structure ("political development") at the end of the rainbow.

At the close of the 1990's, the president of the Association for Asian Studies, David Ludden (2000, 1), remarked that, its usefulness aside, "the production of area-specific knowledge about the world has no firm theoretical foundation." This was readily apparent at the time. Wallerstein instructively draws attention to a 1952 issue of UNESCO'S International Social Science Bulletin devoted to area studies that includes the rebuke that "it is finally possible to imagine - and it would not be such a very extravagant flight of fancy ${ }^{-}$area studies being commissioned by the Defence Ministry or the Foreign Affairs Ministry of this or that country, with a militarist or imperialist aim" (Duroselle, 638).

Indeed the funding and organizational stimulus certainly reflected enough to breed such suspicions. The launching of Sputnik prompted the Eisenhower administration to sign the National Defence Education Act, the Title VI funding of which still, but in much diminished fashion, supports area-studies programs. A number of foundations did much to promote area studies in the major and even minor universities as a legitimate area of study to overcome a perceived knowledge deficit in the wake of the Cold War and anticolonial movements. The Rockefeller Foundation was earliest with its grants starting in 1933 and the initial funds it provided for the Russian Institute at Columbia, the Carnegie Corporation soon followed with funding to Harvard's Russian Research Center in 1948. Most notably the Ford Foundation contributed over \$240 million dollars towards this end, mostly to American universities in the post-war period through its International Training and Research (ITR) program (Bell 1971, 468-469). Wallerstein himself was a recipient of their Foreign Area Fellowship Program grant between 1955-1957.

The mounting suspicions around such a top-down effort at reorganizing social science knowledge quickly culminated into a backlash for all involved with 
the outing of Project Camelot in 1965. Organized through U.S. Army funded Special Operations Research Office (SORO) of American University, the project aimed at a counterinsurgency study. In the words of enthusiastic social psychologist and SORO director Theodore R. Vallance, it did so with the hopes of "developing a general social systems model which would make it possible to predict and influence politically significant aspects of social change in the developing nations of the world" (Galtung 1967, 11). When efforts to enlist the interest of foreign academics reached Norwegian sociologist and later founder of peace and conflict studies, Johan Galtung, he wrote a letter to the project's director refusing participation on the grounds of it "imperialist features." Though the U.S. government would discreetly continue such research, the project was formally canceled almost as soon as it began and its impact of social science and area studies has been a lasting one.

Wallerstein $(1997,225)$ notes the suspicion with which present-based area scholars were treated in foreign countries and how this threatened access to field research bred on "a certain distancing from U.S. scholars, often considered to be agents, if not always wittingly then unwittingly, of U.S. governmental interests." These concerns are all the more prescient when one considers that the project's director feared the possibility of revolution even in the U.S." emergence of a numerically significant, economically powerful, intellectually informed marginal group" (Rohde 2007, 161).

Wallerstein notes that it was indeed this kind of group that refocused area-knowledge by questioning knowledge paradigms that spurred debates over the uses and organization of knowledge, something crucial to the development of world-systems analysis. The contributions from scholars beyond the narrowly focused Western world have potentiated a renewal for the hopes that knowledge production could be used for normative projects outside the founding aspirations of the structures of knowledge; namely the "ordered pace of change", continued capital accumulation, and the maintenance of hegemony. It is here that Wallerstein notes a certain passing of the baton, so to speak, on the deeper aggregate effect area-knowledge has had on the structures-of-knowledge epistemology. In the next section, let us examine this turn and how it contributes to the analyzing of our social prisons that Wallerstein and his movement consider so important.

\section{A Dual-Inheritance}

In thinking of knowledge more openly, ontology is of great aid to practicing a bottom-up approach to understanding the unit of analysis and the act of studying it. Aforementioned, we've seen the categories of "progress", 
"modernity", and "development" forwarded as putatively value-neutral (but somehow nonetheless good) aims justifying the methodologies, subject matters, and ideological stances of the structures of knowledge. This reminds of the supreme importance of the ontological objects, the things we perceive and how we perceive them to be.

For a discipline focusing on abstractly delimited "areas", the threats of catastrophic global climate change, thermonuclear warfare, diminishing water resources and resources of all kinds amid the stranglehold of a late-stage capitalism seemingly indifferent to the unprofitable solutions and at once forestalling individuals from organizing to overcome their restraining structural imperatives, these transformations threaten both the very category of "area" and the meaningfulness of the states that dwell within.

"Areas" are more powerfully explanatory than "states" or "nations" to be sure but less so than the core, peripheral, and semi-peripheral relationships among and within them. That humans are separated into such divisions is an accident of history, which is to say of our own doing. That such conceptual categories carry force at all is, however, an accident of evolution, which is to say not of our doing. Evolutionarily, our brains have evolved to divide the world into objects. Historically, objects, more so the concepts of them (concrete and abstract), have been written over, filled in, been informed by a legacy of discourse and interpretation. Nevertheless, both constitute inheritances, whether from our forebears or more distant ancestors. These two inheritances intersect at the material reality wherein individual agents face a finitude of resources in the task of mediating these objects.

It is in this way that Wallerstein found epistemological connection between the efforts of area-knowledge and the myriad "studies" disciplines. Rather than the objects of "development" or "progress" the notion of justice seemed to reorient the aims of regional scholarship. As Francis X. Sutton noted, introducing the most dedicated book-length account of the Ford Foundation, its "problem orientation" of applying scientific knowledge "was captured by academics who had their own interests to deflect them from dutiful service of the national interest" (Macdonald 1989, xv-xvi). Outside that immediate sanction, too, did post-1968 scholars articulate knowledge of "forgotten peoples" insisting that the present-based, nomothetic epistemologies of the institutionalized disciplines left a wide and meaningful gap in the theoretical preemies of social science. While wholly unintended, the anti-essentializing ontologies of these diverse research aims shared a collective effect on putting the internal contradictions of the third logistic of the structures of knowledge into terminal, bifurcating, crisis. In Wallerstein's words: 
I call these academic enterprises variants of area studies because they too tended to group scholars from multiple traditional disciplines. And they too insisted that their subject matter could neither be studied ahistorically (pre-1945 ethnography and Oriental studies) nor be studied by simple application of nomothetic universalizing social science. . the creation of area studies laid the groundwork for their emergence, first of all by undermining the plausibility of traditional ethnography and Oriental studies, then by forcing the "Western" disciplines to take into account a larger range of data, and finally by questioning the sacrosanct divisions of the disciplines $(1997,227-228)$

Area-knowledge, then, has been a crucial contribution to world-systems analysis' goals of opening up knowledge, and that of the social sciences in particular, as well as rearticulating the received categories through which we discuss and thereby shape our world. Of those most enduring categories are the political ideologies that often preclude the function of study and policy. To that end, before concluding with how Wallerstein felt his project was fairing before his death let us examine a particularly useful insight of his on how to better view the still very impactful ideological pretensions of popular politics.

\section{The "Metastrategies"}

Another hallmark of the world-systems tradition concerns the treatment of political ideologies as metastrategies. Wallerstein ended his fourth and final volume of the history of the modern world system explaining how the creation of the structures of knowledge enforced what he thought of as triumphant centrist liberalism. Rather than taking political ideologies as preconfigured spaces into which we insert ourselves, he asserted them to be the range of possible long-form strategies to deal with the novel conception of modernity, namely the normality of political change. As such, they accord with his project of historicizing analytical categories and lending greater continuity to the agents that make up the structures of the modern world-system.

Accordingly, this analyzes them as programs responding to what Wallerstein often referred to as the "new normal" in the wake of French Revolution. Controversially, he held that there was meaningfully no such revolution in France. Contrasting the perspectives of Soboul's analysis as bourgeois overthrow of the ancien régime and that of Furet and Cobban as liberal uprising against despotism, he notes that France had long been dominated by capitalist elites but that neither France nor England at this time could be said to have had effective "liberal" institutional structures by the end of the eighteenth 
century. Thus a world-systems perspective rejects both major competing interpretations.

Rather, the event is viewed as part of the long struggle for hegemony in the world-system in the vacuum left by that of the Dutch. The 1763 Peace of Paris marked France's loss on the seas, in India, and the Americas; the 1780's brought the aggravated fiscal sowing of what was reaped in involvement with the American revolution; the 1786 acceptance of the Eden Agreement earned France new sources of revenue but had more immediate detrimental effects which compounded the fiscal crises to be addressed by the Estates-General's untimely convening after two successive bad harvest years leading to what Wallerstein (2001, 11) calls "the 'runaway' situation." By 1815, France had "more definitively" been beaten on land, where its greater strength lay, and in contrast to 1789 Britain now enjoyed a much clearer "lead over France in the production of goods for the world markets" (ibid, 12).

From this, Wallerstein contended that the revolution was more revolutionary for those outside France as the international bourgeoisie drew important conclusions from it. One of these was that, unlike the more common bread riots to which they had grown accustomed, this time things were different, for they annunciated, not through their success but through their mere occurrence, that political change was now not only possible but normal. "It was only by accepting the normality of change", Wallerstein (ibid, 15) writes, "that the world bourgeoisie had a chance of containing it and slowing it down."

The initial conservative response to this was an aim at setting back the clock to monarchy, though after the uprisings of 1848 the reactionary path of Prince Metternich and the Holy Alliance was abandoned in favor of the more liberal tactics of England's Sir Robert Peel who exemplified the response that would find expression in centrist liberalism to this day. Peel's success in forestalling radical antisystemic action in 1848 England relied on limited concessions aimed at taking the wind out of radicalism's appeal. This steamvalve-release response to popular demands has been a hallmark of the modern world-system's centrist liberal hegemony as "almost all of the popular movements of the period from 1945 to 1975, even perhaps revolutionary movements, could be seen as demands for inclusion: demands for political equality that assumed equality was meaningless without some level of economic security" (Graeber 2014, 375).

The third of these metastrategies concerns the various strains of socialism, anarchism, and communism but also more broadly the nationalist, irredentist, and identity-based movements in that all have been staunchly antisystemic; that is, they rely on epistemologies that reject the so-called free hand of the market, including the mitigating effects that enable it, in favor of an alternative categorical abstraction from that of capital as the chief organizing principal of society. 
Wallerstein further forwarded the ideological metastrategies (in their parliamentary instantiations) alongside the social sciences and the antisystmic movements operating outside parliamentary sanction as "the institutional underpinnings of what is sometimes inaptly called 'modernity." $(2001,16)$. In this way, Wallerstein at once articulated ideological categories as both beyond mere political associations but also embedded in politics in their response to the birth of popular sovereignty. Making conscious choices to concert collective effort towards a goal means also risking not being sucked into the logic of an ideology's operation as a strategic enterprise.

It might not be that profound a statement to many that one's relationship to money, a given state, party, or ethnicity, or a political ideology is secondary to our shared human bonds and our shared struggle to overcome the pressing transformations facing the world. However, rejecting such abstractions is a much harder sell for a lot of people. More pointedly, it is very difficult to organize around such affiliations. That which we could arguably say is "political" merely concerns the reality that collective decision-making occurs within disagreement. "They Had the Money, We Had the People" Miriam Bensman (2018) titled her piece on the once unlikely victory of Alexandria Ocasio-Cortez. And while it is meant to sound empowering, it really enunciates the opposite. For money, in this way, constitutes a technology (see Habermas' (1984) "steering media") enabling one to separate themselves from people while still enjoying the fruits of their labor. "Having people" as its corollary entails the difficult projects of sustained solidarity and coercion.

We could presume a knowledge project that aims at transforming the channels through which human endeavor is organized. This would have to aim at links both nationally and internationally which would of course entail regionally with the aim of being truly global. I'd assert that these connections already exist among the current agglomerations of associations guiding the status-quo, those of finance-capital and the neoliberal consensus. What would be novel is the effort to construct those that aim at breaking down the fictive barriers humans have inherited between one another in order to address the resultant challenges that face all of us, namely catastrophic global climate change, thermonuclear warfare, late-stage capitalism, resource depletion, and social and economic justice.

\section{Conclusion: Success and Fail States}

If critics are interested in social change, wrote Michael Roth $(1991,419)$, then it is imperative to "preserve a clearing in which their readers can reconnect to a project of political action" and when it closes it is "often the result of the inability to sustain belief in the possibilities of significant social change." This 
echoed the concern of C. Wright Mills, a teacher, mentor of Wallerstein: "simply understanding is an ideal of the man who has a capacity to know truth but not the chance, the skill, or the guts, as the case may be, to communicate [. . . ] with political effectiveness" $(2008,20)$. As a lifelong socialist, Wallerstein was clear about his hopes for the direction the world-system would take and for his knowledge project.

Towards the end of his life he had expressed that the world-system was undergoing bifurcation "and shall continue to [. . ] until probably circa 2050" (2011). The successor system, would likely emerge out of a battle between what he termed the "spirit of Port Alegre" and the "spirit of Davos." This is to refer to the mutually exclusive visions of the World Economic Forum and its competing World Social Forum. That of Davos seeks a "non-capitalist" alternative that nonetheless maintains the hierarchy, exploitation, and environmentally indifferent resource extraction while attempting to anesthetize critique through inviting even critics as strong as Rutger Bregman and Winnie Byanyima (a sort of cosmopolitan globalism). Of the varied positions of the World Social Forum, Wallerstein hoped to see the general spirit of a decommodifying, more democratic and egalitarian world win out (a sort of cosmopolitan humanism).

Achille Mbembe (2016) holds a much more grim opinion of where the world was heading - "The Age of Humanism is Dying" - and diagnosed among its ills that among the categories we use to understand the world, the language through which we articulate it, "the content is in the form and the form is beyond, or in excess of, the content." The form subordinates the individual to the role of channeling its content in service to it, the form is a given, no further analysis or discourse required.

But this was something key to Wallerstein's thought and the insights of area-knowledge. First among his tactics to bring about a more conscious, egalitarian world was to "place great emphasis on serious intellectual analysisnot in a discussion conducted merely by intellectuals, but throughout the populations of the world" (2011). While still an uphill battle this is something already taking shape in the new and unprecedented ways available to share ideas without barrier to entry. Richard Lee lauds "one of the most important concrete developments of the many already underway today" in the form of "the way the divide between the scholarly and non-scholarly is now facing challenge (indeed, the divide between authority figures and those over which they hold sway)" (2012b, 110).

The previously mentioned transitions marking the segue into a new world are unfortunately all quite bad ones. World-systems analysis embraces the embedded observer and from a normative standpoint we could suggest a project that analyzes how the aggregate effect of rising to mitigate those transitions plays itself out. As a broad knowledge project, this means analyzing people as agents 
capable of choosing their reproduction of thought and behavior that constitutes the world-system to come over that of subjects directed by alien forces beyond their power and reckoning. For his own knowledge project, Wallerstein considered the possibility of a certain success by obsolescence. World-systems analysis' success "might be measured by its disappearance as a knowledge movement as a result of the radical reorganization of the world of knowledge" (Wallerstein 2012, 521). But he was also quite clear about what constituted a fail state: "if world-systems analysis ends up as being merely one more theoretical position within the social sciences, it will have failed in what it had hoped to accomplish" (ibid).

Given that Wallerstein (2011) had said that we will not see a better world by 2050 any if any of the "three pending supercalamities occurs: irrevocable climate change, vast pandemics, and nuclear war", it is hard to remain hopeful seeing that as of the time of writing two out of three continue to make daily headlines with no sign of stopping. Systems have a way of absorbing social action within their ability to return to equilibrium but "one encouraging feature about a systemic crisis," Wallerstein (ibid) wrote "is the degree to which it increases the viability of agency."

\section{REFERENCES}

Anderson, Perry. 1974. Lineages of the Absolutist State. London: NLB.

Bell, Peter. 1971. "The Ford Foundation as a Transnational Actor." International Organization 25(3): 465-478.

Bensman, Miriam. 2018. "They had Money, We had People," in Dissent, last modified July 9, 2018, accessed September 29, 2019, <https://www.dissentmagazine.org/ blog/they-had-money-we-had- people-alexandria-ocasio-cortez >

Cameron, Rondo. 1973. "The Logistics of European Economic Growth: A Note on Historical Periodization." Journal of European Economic History 2(1): $145^{-148 .}$

Duroselle, Jean. "Area Studies: Problems of Method," International Social Science Bulletin 4(4): 636-38.

Galtung, Johan. 1967. "Scientific Colonialism." Transition, 30: 10-15.

Graeber, David. 2014. Debt: The First 5,000 Years. London: Melville House.

Habermas, Jürgen. 1984. The Theory of Communicative Action Voll: Reason and the Rationalization of Society. Timothy McCarthy (Trans.), Boston, MA: Beacon Books.

Kemmis, Stephanie and Robin McTaggart. 2005. "Participatory Action Research Communicative Action and the Public Sphere." In The SAGE Handbook of Qualitative Research. Third Edition edited by N. K. Denzin \& Y. S. 
Lincoln. 559-603. Thousand Oaks, CA: SAGE.

Lee, Richard. 2003. "The "Third" Arena: Trends and Logistics in the Geoculture of the Modern World-System." In Emerging Issues in the 21st Century World-System edited by Wilma A. Dunaway, 120-127. Westport, CN: Prager.

Lee, Richard. 2011. "The Structures of Knowledge in a World of Transition.” In Worldviews, Science and Us Interdisciplinary Perspectives on Worlds, Cultures and Society edited by Diederik Aerts, Bart D'Hooghe, Rik Pinxten, and Immanuel Wallerstein, 164-180. Singapore: World Scientific.

Lee, Richard. 2012a. "The Longue Durée, and the Status of Superstructures." In The Longue Durée and World-Systems Analysis edited by Richard Lee, 161-170. Albany: State Univ. of New York Press.

Lee, Richard. 2012b. "The Structures of Knowledge: Conceptualizing the Sociocultural Arena of Historical Capitalism." In Routledge Handbook of World-Systems Analysis edited by Salvatore J. Babones and Christopher Chase-Dunn, 104-111. London: Routledge.

Ludden, David. 2000. "Area Studies in the Age of Globalization." Frontiers: An international Journal of Study Abroad 6(1): 1-22.

Macdonald, Dwight. 1989. The Ford Foundation: The Men and the Millions. Oxford: Transaction Publishers.

Mbembe, Achille. 2016. "The Age of Humanism is Ending," in Mail \& Guardian, last modified December 22, 2016, accessed December 16, 2019, https://mg.co.za/article/2016-12-22-00-the-age-of-humanism-is-ending/ Mills, Wright. C. 2008. The Politics of Truth: Selected Writings of C. Wright Mills edited by John Summers, New York: Oxford University Press.

Oakeshott, Michael. 1971. "Education: The Engagement and its Frustration." in Journal of Philosophy of Education 5(1): 43-76.

Poovey, Mary. 1998. A History of the Modern Fact: Problems of Knowledge in the Sciences of Wealth and Society, Chicago: University of Chicago Press.

Rohde, Joy. 2007. "'The Social Scientists' War': Expertise in a Cold War Nation." (Ph.D dissertation, University of Pennsylvania).

Roth, Michael, S. 1991. “The Ironist Cage.” Political Theory 19(3): 419-432.

Skocpol, Theda. 1977. "Wallerstein's World Capitalist System: A Theoretical and Historical Critique." American Journal of Sociology. 82(5): 1075-1090.

Stremlin, Boris. 2008. "Constructing Authority: The Rise of Science in the Modern World." In Overcoming the Two Cultures: Science versus the Humanities in the Modern World-System edited by Richard E. Lee and Immanuel Wallerstein, 9-33. Boulder, Colorado: Paradigm Publishers.

Wallerstein, Immanuel. 1997. "The Unintended Consequences of Cold War Area Studies" In The Cold War \& The University Toward and Intellectual History of the Postwar Years edited by Noam Chomsky, 195-231. New 
York: The New Press.

Wallerstein, Immanuel. 1998. "The Rise and Future Demise of World-Systems Analysis" Review (Fernand Braudel Center). 21(1): 103-112.

Wallerstein, Immanuel. 2001. Unthanking Social Science: The Limits of Nineteenth-Century Paradigms. Philadelphia: Temple University Press.

Wallerstein, Immanuel. 2007. World-Systems Analysis: An Introduction. Durham and London: Duke University Press.

Wallerstein, Immanuel. 2011. "Structural Crisis in the World-System: Where Do We Go from Here?" in Monthly Review, last modified March $1^{\text {st }}, 2011$, accessed February $19^{\text {th }}, 2020$, https://monthlyreview.org/2011/03/01/structuralcrisis-in-the-world-system/

Wallerstein Immanuel. 2012. "World-Systems Analysis as a Knowledge Movement. In Routledge Handbook of World-Systems Analysis edited by Salvatore J. Babones and Christopher Chase-Dunn, 515-521. Oxford: Routledge. 